\title{
The effect of ultrasound-related stimuli on cell viability in microfluidic channels
}

\author{
Dyan N Ankrett ${ }^{1 *+}$, Dario Carugo ${ }^{1,2 \dagger}$, Junjun Lei ${ }^{1}$, Peter Glynne-Jones ${ }^{1}$, Paul A Townsend ${ }^{3}$, Xunli Zhang ${ }^{2}$ \\ and Martyn Hill ${ }^{1}$
}

\begin{abstract}
Background: In ultrasonic micro-devices, contrast agent micro-bubbles are known to initiate cavitation and streaming local to cells, potentially compromising cell viability. Here we investigate the effects of US alone by omitting contrast agent and monitoring cell viability under moderate-to-extreme ultrasound-related stimuli.

Results: Suspended H9c2 cardiac myoblasts were exposed to ultrasonic fields within a glass micro-capillary and their viability monitored under different US-related stimuli. An optimal injection flow rate of $2.6 \mathrm{~mL} / \mathrm{h}$ was identified in which, high viability was maintained ( 95\%) and no mechanical stress towards cells was evident. This flow rate also allowed sufficient exposure of cells to US in order to induce bioeffects $(\sim 5 \mathrm{sec})$, whilst providing economical sample collection and processing times. Although the transducer temperature increased from ambient $23^{\circ} \mathrm{C}$ to $54^{\circ} \mathrm{C}$ at the maximum experimental voltage $\left(29 \mathrm{~V}_{p p}\right)$, computational fluid dynamic simulations and controls (absence of US) revealed that the cell medium temperature did not exceed $34^{\circ} \mathrm{C}$ in the pressure nodal plane. Cells exposed to US amplitudes ranging from 0-29 $V_{p p}$ at a fixed frequency sweep period ( $t_{s w}=0.05 \mathrm{sec}$ ), revealed that viability was minimally affected up to $\sim 15 V_{p p}$. There was a $\sim 17 \%$ reduction in viability at $21 V_{p p}$, corresponding to the onset of Rayleigh-like streaming and a $\sim 60 \%$ reduction at $29 V_{p p}$, corresponding to increased streaming velocity or the potential onset of cavitation. At a fixed amplitude $\left(29 \mathrm{~V}_{p p}\right.$ ) but with varying frequency sweep period ( $\mathrm{t}_{\mathrm{sw}}=0.02-0.50 \mathrm{sec}$ ), cell viability remained relatively constant at $t_{s w} \geq 0.08 \mathrm{sec}$, whilst viability reduced at $t_{s w}<0.08 \mathrm{sec}$ and minimum viability recorded at $\mathrm{t}_{\mathrm{sw}}=0.05 \mathrm{sec}$.

Conclusion: The absence of CA has enabled us to investigate the effect of US alone on cell viability. Moderate-to-extreme US-related stimuli of cells have allowed us to discriminate between stimuli that maintain high viability and stimuli that significantly reduce cell viability. Results from this study may be of potential interest to researchers in the field of US-induced intracellular drug delivery and ultrasonic manipulation of biological cells.
\end{abstract}

Keywords: Ultrasound (US), Micro-device, Cardiac myoblasts, Cell viability

\section{Background}

In ultrasonic cell stimulation micro-devices, the inclusion of ultrasound (US) contrast agent (CA) to enhance US bioeffects or increase cell membrane permeability is common [1]. However, CAs can initiate cavitation and streaming [2] local to cells, potentially compromising cell viability $[3,4]$. Thus, higher cell viability is likely to be maintained in the absence of CA [5-7]. In our previous study we reported

\footnotetext{
* Correspondence: D.Ankrett@soton.ac.uk

${ }^{\dagger}$ Equal contributors

'Electromechanical Engineering Group, Faculty of Engineering and the Environment, University of Southampton, Southampton SO17 1BJ, UK Full list of author information is available at the end of the article
}

on ultrasonically induced membrane poration of a cardiac myoblast cell line (H9c2) in the absence of CA by generating an ultrasonic field within a biocompatible glass micro-capillary [3]. Notably, high cell viability was maintained in the absence of CA [3]. Following a similar approach, Longsine-Parker et al. recently demonstrated effective cell membrane poration in a microfluidic device by combining the action of electric fields and US waves in a CA-free environment [8].

Here we investigate US-"alone"-related physical stimuli of H9c2 cells. We expose suspended cells to gentle, moderate and extreme US amplitudes. Extreme amplitudes also initiate an increase in transducer temperature; therefore we also

\section{Biomed Central}


investigated the effect of US-related temperature increase on cell viability. Cell viability was also measured following infusion into the micro-device at varying flow regimes in order to optimise the flow rate. Of particular interest to us is the effect of frequency sweeping on cells as a means of controllably stressing cells and potentially increasing membrane permeability.

\section{Results}

Cells were subjected to a variety of US-related stimuli (summarised in Table 1) in order to assess the effect of US alone on cell viability in the absence of CA.

At $2.6 \mathrm{~mL} / \mathrm{h}$ viability was uncompromised, likely due to low mechanical stress (Figure 1). This flow rate also provided economical sample collection and processing times whilst allowing sufficient exposure of cells to US $\left(t_{\exp } \cong 5 \mathrm{sec}\right)$ for generating observable bioffects. Furthermore, no cell trapping was evident, providing homogeneous exposure of cells to US.

During US applied at the maximum experimental voltage, $29 V_{p p}$, the transducer temperature was noted to increase from ambient $23^{\circ} \mathrm{C}$ to a biologically unfavourable $54^{\circ} \mathrm{C}$. However, CFD simulations revealed that the temperature of the liquid medium at the capillary centerline only increased up to a maximum of $\sim 34^{\circ} \mathrm{C}$ (Figure $2 \mathrm{a}$ ). To validate the simulations, control experiments (absence of US), replacing the transducer with a hot plate fixed at $54^{\circ} \mathrm{C}$, revealed that cell viability was minimally affected $(92.12 \pm 2.94 \%)$, while during US exposure at $29 V_{p p}$, viability reduced to 43.28 $\pm 5.54 \%$ (Figure 2b). This suggests that PZT heating per se did not compromise cell viability. However, the CFD simulations did not take into account the effect of acoustic streaming on heat transfer within the fluidic domain, which may have contributed to the reduction in cell viability.

Cell viability was measured immediately following exposure to US amplitudes ranging from $0-29 V_{p p}$, using a fixed frequency sweep period of $0.05 \mathrm{sec}$. Figure 3 demonstrates that cell viability was not compromised up to $\sim 15 V_{p p}$. However a $\sim 17 \%$ reduction in cell viability was measured at $21 V_{p p}$, corresponding to the onset of streaming, assigned

Table 1 Summary of the experiments performed to investigate the effect of US-related stimuli on $\mathrm{H} 9 \mathrm{c2}$ cell viability

\begin{tabular}{lll}
\hline Experiment & Operating conditions & Figure \\
\hline $\begin{array}{l}\text { Flow rate through } \\
\text { the micro-capillary }\end{array}$ & Inlet flow rate: 1.3-13.0 mL/h & Figure 3 \\
& $\begin{array}{l}\text { PZT temperature measurements } \\
\text { and CFD simulations of fluid } \\
\text { temperature distribution }\end{array}$ & Figure 4a \\
$\begin{array}{l}\text { US-induced thermal } \\
\text { variations }\end{array}$ & $\begin{array}{l}\text { Controls (correspondent PZT } \\
\text { temperatures, absence of US) }\end{array}$ & Figure 4b \\
Amplitude variations & Driving voltage: 6-29 Vp & Figure 5 \\
Sweep period variations & Sweep period: 0.02-0.50 sec & Figure 1 \\
\hline
\end{tabular}

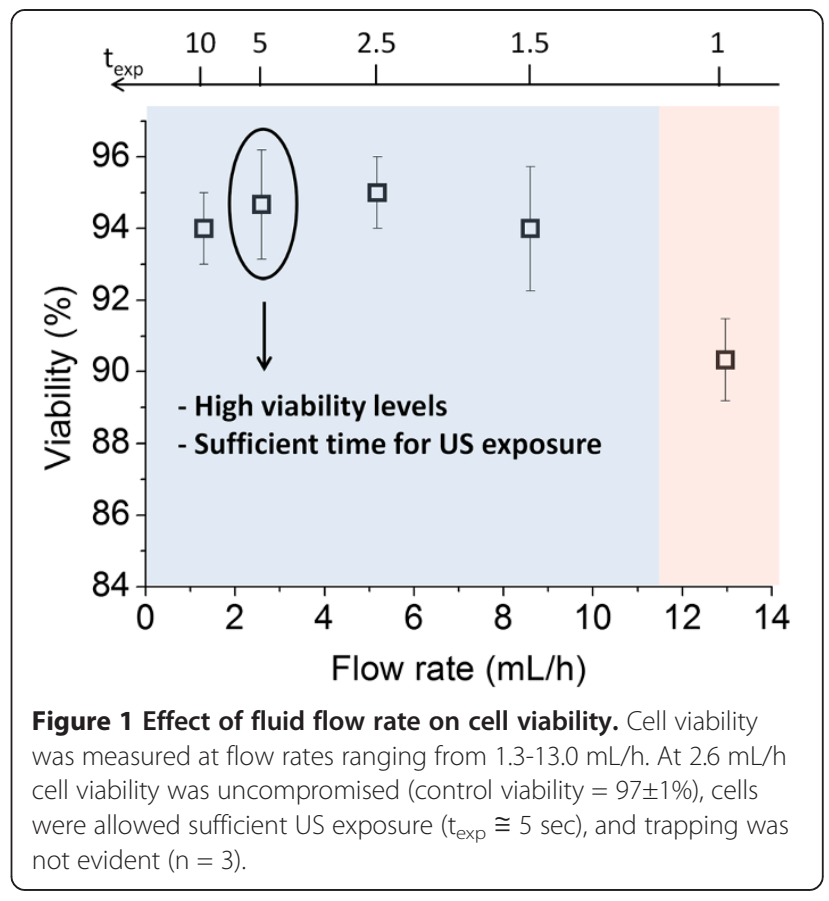

as Rayleigh-like (observed with fluorescent tracers under static conditions), characterised by the formation of toroidal axially centred vortices [10]. A $\sim 60 \%$ viability reduction was measured at $29 V_{p p}$, corresponding to an observed increase of the streaming velocity. Furthermore, the acoustic pressure (measured by drop-voltage analysis at a fixed $f=2.18 \mathrm{MHz}$ ) was $\sim 2.05 \times 10^{4} \times V_{p p}$ Pa. This corresponded to pressures in the range $0.12-0.59 \mathrm{MPa}$, thus suggesting that cavitation may have occurred at $V_{p p}>20$. Notably, Apfel and Holland determined a minimum pressure threshold of $\sim 0.4 \mathrm{MPa}$ for cavitation to occur in water, at a frequency of $\sim 2 \mathrm{MHz}[6,11]$.

At a fixed amplitude $\left(29 V_{p p}\right)$ but varying the sweep period $\left(t_{\mathrm{sw}}=0.02-0.50 \mathrm{sec}\right)$, cell viability was virtually unaffected by frequency sweep periods $t_{\mathrm{sw}} \geq 0.08 \mathrm{sec}$. However, at sweep periods $t_{\mathrm{sw}}<0.08 \mathrm{sec}$ cell viability decreased, with minimum viability $(\sim 41 \%)$ measured at $\mathrm{t}_{\mathrm{sw}}=0.05 \mathrm{sec}$ (Figure 4a). Under identical acoustic conditions, $20 \mu \mathrm{m}$ diameter fluorescent beads were observed to rapidly oscillate across a relatively smaller distance away from the nodal plane at $t_{\mathrm{sw}}=0.1 \mathrm{sec}$, compared with $\mathrm{t}_{\mathrm{sw}}=0.5 \mathrm{sec}$ where bead oscillation was visibly slower over increased distances away from the nodal plane (Figure $4 \mathrm{~b}$ ).

\section{Discussion}

The effect of individual US-related physical parameters (fluid flow rate, US heat generation, amplitude and frequency sweep period) on H9c2 cell viability was assessed within a microfluidic device. The optimised flow rate did not inflict any detectable mechanical stress, and thus high cell viability was maintained. Moreover cells were allowed 

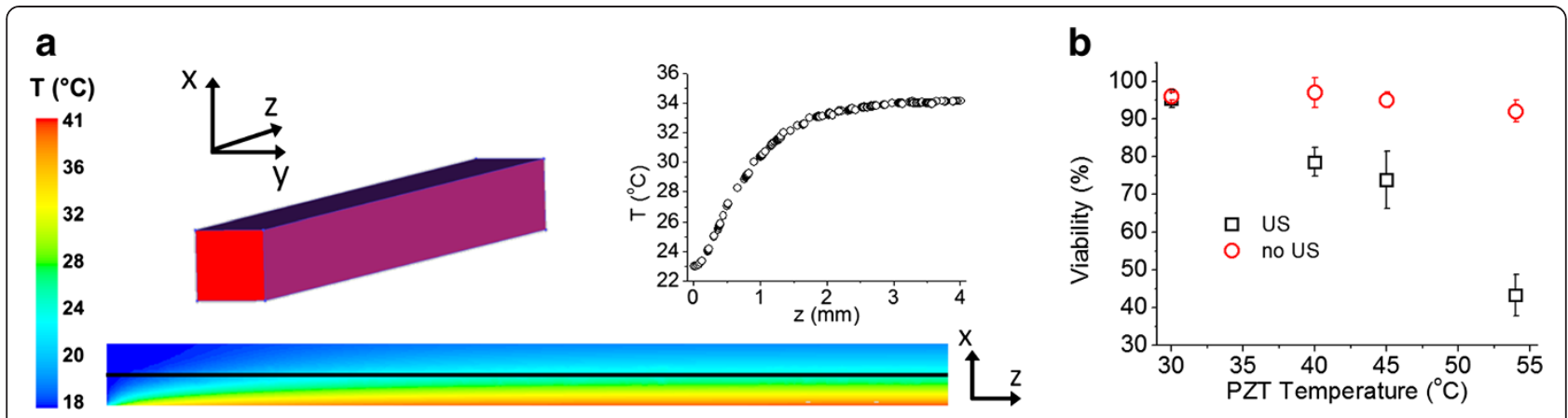

Figure 2 Effect of temperature on cell viability. a] Fluid temperature profile along the glass microchannel centerline and contours of fluid temperature determined computationally. b] Cell viability during US exposure (black squares), and absence of US (red circle) with PZT substituted by a hot plate at corresponding temperatures $(n=4)$.

sufficient exposure to US in order to elicit bioeffects, whilst providing economical sample processing times and minimising cell trapping. High cell viability was maintained at amplitudes where streaming was not evident. However, when more extreme amplitudes were employed, streaming velocities increased and cell viability significantly decreased. Extreme amplitudes also initiated an increase in PZT temperature, however cell viability was unaffected by this increase due to heat dissipation, confirmed by controls and CFD simulations. Longer duration frequency sweeps were identified to have little or no effect on cell viability, whereas short sweeps resulted in reduced cell viability. This effect may be attributed to mechanical stress generated by rapid oscillatory movements of the cell within the fluidic domain [12]. Notably, experiments with fluorescent tracer beads revealed that bead oscillation frequency increased with reducing the sweep interval, which may explain the reduction in cell viability at the

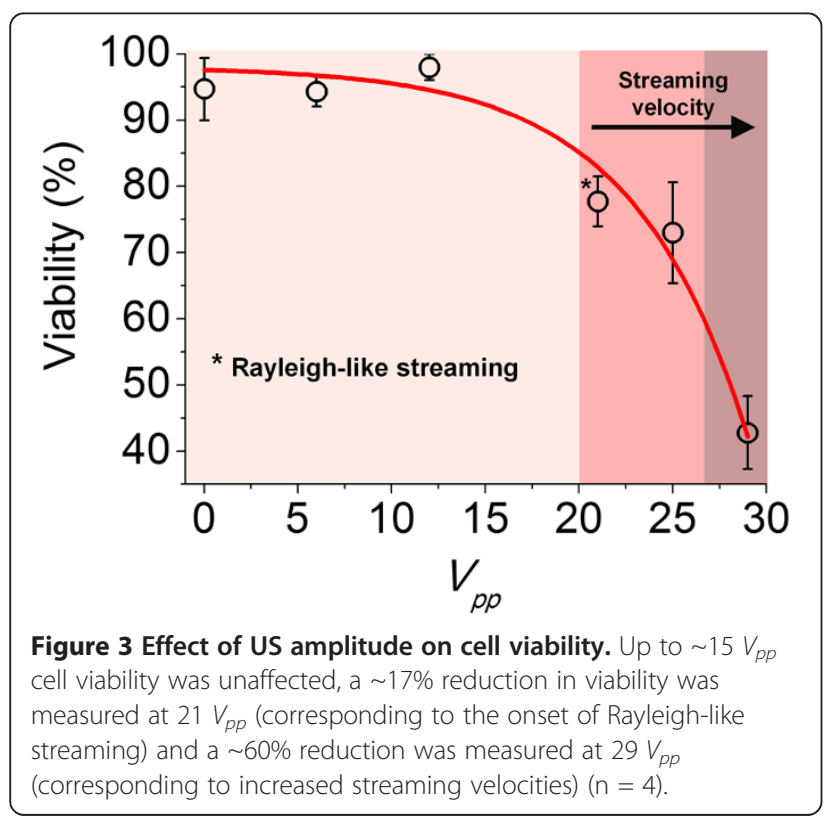

shorter $t_{\text {sw }}$. However, an in depth investigation into the effects of frequency sweeping on cell viability is currently underway in our laboratories.

\section{Conclusion}

Our CA-free investigation into the effects of US on cell viability has enabled us to discriminate between US-related stimuli that do not compromise cell viability and stimuli that significantly reduce cell viability within our micro-device. Our findings may be of potential interest to researchers in the field of US-induced intracellular drug delivery and ultrasonic manipulation of biological cells.

\section{Methods}

The micro-device (Figure 5a), comprising of a squared cross-section borosilicate glass micro-capillary (length: $50 \mathrm{~mm}$, internal width: $300 \mu \mathrm{m}$, wall thickness: $150 \mu \mathrm{m}$; VitroCom, Ilkley, UK), was acoustically coupled to a piezoelectric transducer (PZT; PZ26 Ferroperm, Kvistgard, Denmark) using glycerol. The transducer (length: $40 \mathrm{~mm}$, width: $9 \mathrm{~mm}$ and thickness: $1 \mathrm{~mm}$ ) was fixed to a glass platform and driven by an RF power amplifier (240 L ENI, New York, USA) fed from a signal generator (TG103 TTI, Cambridgeshire, UK). A time varying ultrasonic field was generated within the capillary and the operating frequency determined through electrical impedance measurements (C-60 impedance analyser, Cypher Instruments Ltd., London, UK) of the capillary both air-filled and fluidfilled (Figure $2 b$ ).

H9c2 cardiac myoblasts were grown in Dulbecco's Modified Eagle Medium (DMEM) culture medium supplemented with $10 \%(\mathrm{v} / \mathrm{v})$ foetal calf serum and $1 \%(\mathrm{v} / \mathrm{v})$ penicillin-streptomycin (media and supplements purchased from Fisher Scientific, Loughborough, UK). Cells were maintained at $37^{\circ} \mathrm{C}, 5 \% \mathrm{CO}_{2}$ in air with $95 \%$ humidity. Cells were routinely harvested and suspended at a density of $2 \times 10^{6}$ cells $/ \mathrm{mL}$ in serum free DMEM within a $1 \mathrm{~mL}$ sterile, plastic syringe (BD Bioscience, Oxford, UK). 

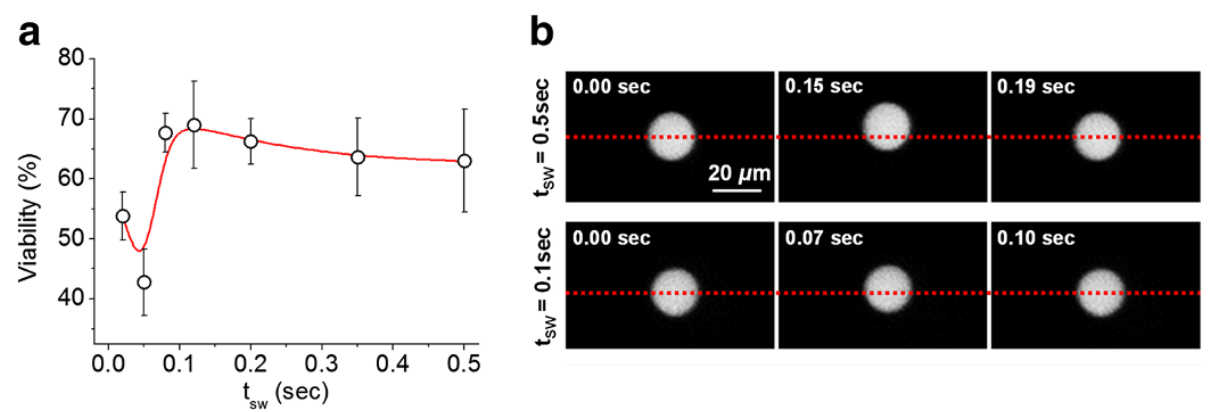

Figure 4 Effect of frequency sweep on cell viability and bead oscillatory dynamics. a] Cell viability was unaffected by $t_{s w} \geq 0.08$ sec but decrease $\geq 0.08 \mathrm{sec}$ using a frequency range: $2.13-2.40 \mathrm{MHz}$ and at a fixed $29 V_{p p}$. b] Oscillatory dynamics of $20 \mu \mathrm{m}$ diameter fluorescent polystyrene beads at a sweep period of 0.5 and $0.1 \mathrm{sec}$.

Cells were infused into the device using a syringe pump (KD100, KD Scientific Inc., Holliston, USA) and subjected to ultrasound-related physical stimuli. Cells were captured in $1 \mathrm{~mL}$ sterile tubes, followed by counting and viability assessment using a Neubauer haemocytometer (depth: $0.1 \mathrm{~mm}$, area: $0.04 \mathrm{~mm}^{2}$ ) and trypan blue exclusion dye. All viability measurements were in triplicate or greater.

To optimise the flow rate, cell viability was measured following infusion into the device at a range of flow rates $(1.3-13.0 \mathrm{~mL} / \mathrm{h})$, which were prior calculated in order to: i) provide sufficient exposure of cells to US, ii) provide economical cell collection and processing times, iii) minimise flow-induced mechanical stress on cells and iv) minimise cell trapping.

To assess US-related thermal effects on cell viability, cells were infused into the device at a fixed flow rate $(2.6 \mathrm{~mL} / \mathrm{h})$ and exposed to US $\left(6-29 V_{p p}\right)$, whilst thermocouples were attached to the transducer, and temperatures recorded using a thermometer (HH11 Omega ${ }^{\circledR}$, Manchester, UK). Controls were produced in the absence of US by replacing the transducer with a hot plate (Fisher Scientific, Loughborough, UK) at identical temperatures to the recorded transducer temperatures. Additionally, computational fluid dynamic (CFD) simulations were performed to predict the transfer of heat from the transducer to the cell medium within the capillary.

The effect of US amplitude on cell viability was investigated by varying the $V_{p p}$, ranging from $0-29 V_{p p}$, using a fixed frequency sweep period of $0.05 \mathrm{sec}$ in the frequency range 2.13-2.40 $\mathrm{MHz}$. Additionally, flow visualisation experiments, using $1 \mu \mathrm{m}$ diameter fluorescent tracers (Polysciences, Inc., Warrington, USA), were performed to characterise the fluid dynamic environment under "gentle" $\left(6 V_{p p}\right)$ to "extreme" $\left(29 V_{p p}\right)$ US amplitudes. The acoustic pressure within the capillary was measured through drop-voltage analysis [9], using $20 \mu \mathrm{m}$ diameter fluorescent polystyrene beads. A fixed resonance frequency of $2.18 \mathrm{MHz}$ was set in this case, due to the difficulty in obtaining acoustic pressure values during frequency sweeping.

The effect of frequency sweep duration on cell viability was investigated by varying the sweep period $(0.02-0.50 \mathrm{sec})$ at a fixed voltage $\left(29 V_{p p}\right)$.
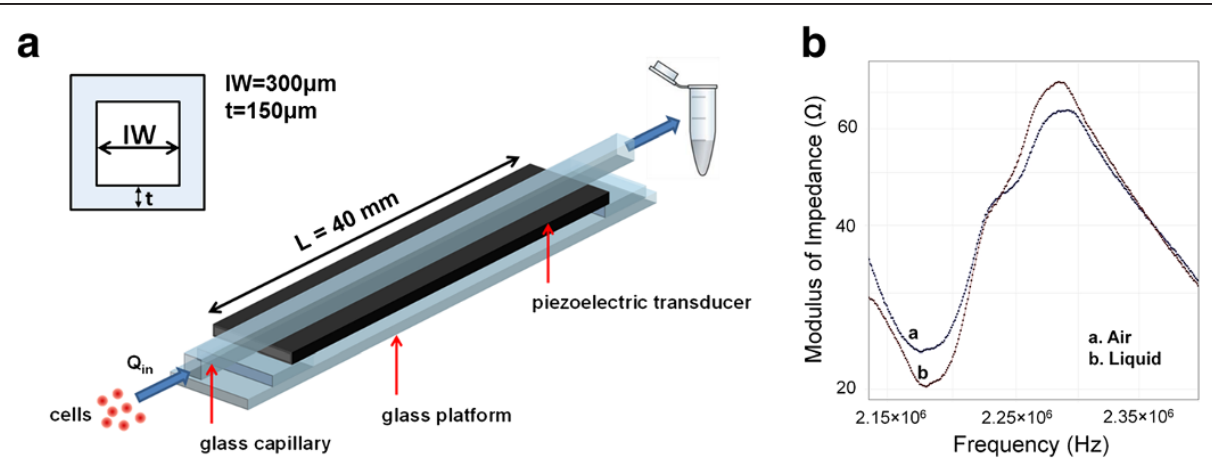

Figure 5 Microfluidic device. a] device comprising of a squared cross-section glass capillary (length: 50 mm, internal width: $300 \mu \mathrm{m}$ and wall thickness: $150 \mu \mathrm{m}$ ), coupled to a PZT transducer (length: $40 \mathrm{~mm}$, width: $9 \mathrm{~mm}$ and thickness: $1 \mathrm{~mm}$ ) and mounted on a glass platform. b] Modulus of impedance $(\Omega)$ for the air-filled and the liquid-filled micro-capillary, respectively. Frequency range: $2.13-2.40 \mathrm{MHz}$. 


\section{Competing interests}

The authors declare that they have no competing interests.

\section{Authors' contributions}

Conceived, designed and performed experiments: DA and DC. Data analysis: DA and DC. Wrote the paper: DA and DC. Device design: PGJ. Invaluable advice provided on microfluidics: XZ, acoustics: $J L$ and $M H$ and biology: PAT. All authors read and approved the final manuscript.

\section{Acknowledgements}

We are very grateful to Agilent Technologies, Santa Clara, CA, USA for funding this research (University Relations Grant 2012, Gift\# 2700).

\section{Author details}

'Electromechanical Engineering Group, Faculty of Engineering and the Environment, University of Southampton, Southampton SO17 1BJ, UK. ${ }^{2}$ Bioengineering Sciences Group, Faculty of Engineering and the Environment, University of Southampton, Southampton SO17 1BJ, UK ${ }^{3}$ Faculty Institute for Cancer Sciences, Faculty of Medical and Health Sciences, Manchester Academic Health Science Centre, University of Manchester, Manchester M13 9WL, UK.

Received: 17 June 2013 Accepted: 17 June 2013

Published: 28 June 2013

\section{References}

1. Le Gac S, Zwaan E, Van Den Berg A, Ohl C-D: Sonoporation of suspension cells with a single cavitation bubble in a microfluidic confinement. Lab Chip 2007, 7(12):1666-1672.

2. Collis J, Manasseh R, Liovic P, Tho P, Ooi A, Petkovic-Duran K, Zhu Y: Cavitation microstreaming and stress fields created by microbubbles. Ultrasonics 2010, 50(2):273-279.

3. Carugo D, Ankrett DN, Glynne-Jones P, Capretto L, Boltryk RJ, Zhang X, Townsend PA, Hill M: Contrast agent-free sonoporation: the use of an ultrasonic standing wave microfluidic system for the delivery of pharmaceutical agents. Biomicrofluidics 2011, 5(4):044108.

4. Brayman AA, Azadniv M, Cox C, Miller MW: Hemolysis of albunex-supplemented, $40 \%$ hematocrit human erythrocytes in vitro by $1-\mathrm{MHz}$ pulsed ultrasound: Acoustic pressure and pulse length dependence. Ultrasound Med Biol 1996, 22(7):927-938.

5. Hultström J, Manneberg O, Dopf K, Hertz HM, Brismar H, Wiklund M: Proliferation and viability of adherent cells manipulated by standing-wave ultrasound in a microfluidic chip. Ultrasound Med Biol 2007, 33(1):145-151.

6. Wiklund M: Acoustofluidics 12: Biocompatibility and cell viability in microfluidic acoustic resonators. Lab Chip 2012, 12:2018-2028.

7. Evander M, Johansson L, Lilliehorn T, Piskur J, Lindvall M, Johansson S, Almqvist M, Laurell T, Nilsson J: Noninvasive acoustic cell trapping in a microfluidic perfusion system for online bioassays. Anal Chem 2007, 79(7):2984-2991.

8. Longsine-Parker W, Wang H, Koo C, Kim J, Kim B, Jayaraman A, Han A: Microfluidic electro-sonoporation: a multi-modal cell poration methodology through simultaneous application of electric field and ultrasonic wave. Lab Chip 2013, 13:2144-2152.

9. Glynne-Jones P, Boltryk RJ, Hill M, Zhang F, Dong L, Wilkinson JS, Melvin T, Harris NR, Brown T: Flexible acoustic particle manipulation device with integrated optical waveguide for enhanced microbead assays. Anal Sci 2009, 25(2):285-291.

10. Sorando AC, Hawkes JJ, Fielden PR, González I: Patterns of particles aggregation and streaming in resonating fluids. AIP Conference Proceedings 2012, 1433:757.

11. Apfel RE, Holland CK: Gauging the likelihood of cavitation from short-pulse, low-duty cycle diagnostic ultrasound. Ultrasound Med Biol 1991, 17(2):179-185,

12. Radel S, McLoughlin A, Gherardini L, Doblhoff-Dier O, Benes E: Viability of yeast cells in well controlled propagating and standing ultrasonic plane waves. Ultrasonics 2000, 38(1):633-637.

\section{doi:10.1186/1477-3155-11-20}

Cite this article as: Ankrett et al.: The effect of ultrasound-related stimuli on cell viability in microfluidic channels. Journal of Nanobiotechnology 2013 11:20.

\section{Submit your next manuscript to BioMed Central and take full advantage of:}

- Convenient online submission

- Thorough peer review

- No space constraints or color figure charges

- Immediate publication on acceptance

- Inclusion in PubMed, CAS, Scopus and Google Scholar

- Research which is freely available for redistribution 